\title{
THE TROUBLE WITH “ARTICULATORY” PAUSES*
}

\author{
ADOLF E. HIEKE \\ Universität Bayreuth \\ SABINE KOWAL \\ Technische Universität Berlin \\ DANIEL C. O'CONNELL \\ Loyola University of Chicago
}

\begin{abstract}
The historical provenance of a minimum cut-off point (of about $0.25 \mathrm{sec}$ ) for pauses in temporal analyses of speech production is associated with Goldman-Eisler's usage. Her rationale was the predominance of articulatory pauses at lengths shorter than $0.25 \mathrm{sec}$. Both phonotactic facts and empirical analysis of several corpora of readings disconfirm this predominance with respect to pauses $0.13-0.25 \mathrm{sec}$ in length. The vast majority of these pauses are found to be psychological; they are determined by syntax, punctuation, thetorical and expressive emphasis, poetic format, and stylistic pecularities.
\end{abstract}

\section{THE BACKGROUND}

In recent years there has been an increasing concern in psycholinguistics with language production. One of the main analytic tools of empirical research in this area has become the silent pause, a period of vocal inactivity of a certain duration embedded in the stream of speech. The methodological development is well documented in a variety of recent publications on temporal aspects of speech (e.g., Butterworth, 1980; Dechert and Raupach, 1980a, b.; Siegman and Feldstein, 1979).

The development of pause analysis was, of course, largely dependent on the availability of adequate recording and transcription equipment (see O'Connell and Kowal, 1983), although pauses have also been assessed perceptually by some researchers (e.g., Maclay and Osgood, 1959). The use of instrumental pause analysis, while solving some methodological problems, has also posed new problems. Instrumental analysis allows for the reliable identification and location of pauses relatively independently of the language habits and perceptual limitations of the human observer, but it has also shown that ordinary discourse is interspersed with pauses of short duration, often below the perceptual threshold of a human observer.

The issue to be discussed in this article pertains to the status of these brief interruptions in speech and specifically their relevance in psycholinguistic research. Our thesis is that, on the basis of phonotactic as well as psycholinguistic research, the position (e.g., Goldman-Eisler, 1968; Grosjean and Deschamps, 1975) that brief pauses in connected discourse reflect primarily an articulatory origin is not tenable. Instead we will argue that brief pauses $(0.13-0.25 \mathrm{sec}$ in length) can be systematically related to psychological and

* The research on political speeches reported in the following has been supported by a Deutsche Forschungsgemeinschaft Habilitationsstipendium granted to Sabine Kowal. 
textual factors.

As research on speech production has developed, it has become customary to choose a minimum cut-off point of $0.2-0.3 \mathrm{sec}$ for pause measurements; however, a number of researchers have adopted much lower or higher cut-off points, ranging from no cut-off point (Henze, 1953; Wilkes and Kennedy, 1969), through $0.08 \mathrm{sec}$ (e.g., Levin, Silverman and Ford, 1967), $0.1 \mathrm{sec}$ (e.g., Butcher, 1981), and $0.15 \mathrm{sec}$ (e.g., Esser, 1977), to > 2 sec (e.g., Siegman, 1979).

The historical impetus for a cut-off point was provided by Goldman-Eisler (1958). She argued that gaps in phonation of less than $0.25 \mathrm{sec}$ are largely determined "by the need to adjust the position of articulation" (1968, p. 12) and should therefore not be included in the analysis of pauses, since they serve no cognitive function in speech production. Additional reasons to the one given by Goldman-Eisler for the use of some cut-off point include limitations in measurement accuracy and in the perceptual ability of the hearer.

Let us briefly consider these latter reasons before returning to the central issue of Goldman-Eisler's rationale. For a variety of reasons a number of researchers have chosen relatively high cut-off points for pause measurement or have declined to quantify pause length at all. Levin and Silverman (1965) defined pauses as those silent intervals longer than $1 \mathrm{sec}$ in duration, measured to the closest whole second with a stop watch. Lay and Paivio (1969) recorded only pauses of approximately $1 \mathrm{sec}$ or more. Siegman and Pope (1966) adopted a minimum criterion of $3 \mathrm{sec}$ for pauses. Maclay and Osgood (1959) defined pauses, with no quantification of length, by judgment: "These were marked when there was judged to be an abnormal hesitation in speech that could not be referred to the three previous categories [repeats, false starts, and filled pauses]" (1959, p. 24).

On the assumption that pauses are used by the listener to construe the meaning of an utterance, perceptual thresholds for pause detection as a function of their length have been investigated experimentally. Results of this research have been reviewed by Rochester (1975/76) and Esser (1977). From three such studies (Boomer and Dittmann, 1962; Cowan and Bloch, 1948; and Martin, 1970), Rochester concluded:

Long pauses are always detected and no further variables are needed for explanation, while detection of short pauses (50-200 msec in Cowan \& Bloch's work; 50-110 msec in Martin's study) depends on linguistic cues. (Rochester, 1975/76, p. 3)

In the same vein, Butcher observed that

Whereas breaks between tone groups are not heard by $75 \%$ of listeners until they are approximately $220 \mathrm{~ms}$ long, breaks within tone groups are heard by the same proportion of listeners when only $80 \mathrm{~ms}$ long. (Butcher, 1981, p. 205)

After reviewing the empirical literature concerned with the determination of a minimum cut-off point on the basis of perceptibility, Esser (1977) rejected such an approach:

The determination of minimum pause length must instead start from the question: How much time does a speaker need to carry out an elementary cognitive-linguistic operation in speech production? (1977, p. 114; our translation) 
He himself chose $0.15 \mathrm{sec}$ as a cut-off point.

A twofold corollary follows from these discrepancies in pause measurement: Existing research results cannot very easily be compared with one another on the one hand, and on the other the more theoretical question as to what constitutes psychologically functional pause time for the speaker (and the listener), tempus utile, cannot be answered as long as cut-off points are chosen quite arbitrarily and variably from one research project to another.

The predicament for pause analysis has been noted frequently and with increasing urgency (e.g., Rochester, 1975/76; Esser, 1977). Excepting speech rate, all temporal response measures are affected by the choice of a cut-off point for silent pauses: Within any given speech sample, the lower the cut-off point the higher the percentage of pause time, the faster the articulation rate (because it is determined by the rapidity of syllable production, exclusive of pause time), the shorter the mean phrase length (in terms of syllables per pause) and mean pause length (because more and shorter pauses are recorded). The regrettable consequence has been that a considerable amount of data otherwise available for interpretation has been lost, precisely because of the differences in criteria employed in pause analysis.

\section{PHONETIC FACTS REgARDING “ARTICULATORY” PAUSES}

To return to Goldman-Eisler's rationale for a cut-off point, it will be remembered that her emphasis was on the articulatory function of short pauses for the speaker:

Phonetic stoppage is part of articulation itself and the gaps in phonation are determined by the need to adjust the position of articulation. To be quite certain that no such gaps are included in our record, breaks in phonation of less than $.25 \mathrm{sec}$ were not considered as discontinuities. This might mean loss of some data, but it ensures the clear separation of hesitation pauses from phonetic stoppages. (Goldman-Eisler, 1968, p. 12)

Goldman-Eisler held that pauses $<0.25 \mathrm{sec}$ can occur in speech production "as part of ritardando effects, or articulatory shifts, or between plosives" (1958, p. 99), in particular:

The discontinuity of phonation which occurs in articulatory shifts, e.g. when two plosives or stops follow each other (e.g. top part, rat tat). In such a case the breath stress is completely stopped and then released anew. (Goldman-Eisler, 1968, p. 12)

Her reasoning, while perhaps not terminologically felicitous, was adopted and resulted in a standard, fairly uncritical attitude to the effect that "many of the shorter 'pauses' reflect only necessary phonational discontinuities" (O'Connell, Kowal and Hörmann, 1969 , p. 52). A similar claim has appeared more recently:

Articulatory stop closure ... may range in duration from $50 \mathrm{msec}$ to as much as $250 \mathrm{msec}$, depending partly on such factors as the place of closure, the manner of closure, the articulatory organ or organs involved, the surrounding sounds, and suprasegmental features such as rhythm, stress or overall utterance rate. (Dalton and Hardcastle, 1977, p. 33; but see the formulation of Butcher, 1981, p. 44) 
Goldman-Eisler's rationale for suggesting a cut-off point of $0.25 \mathrm{sec}$ fails to take into consideration two important factors that are well established in phonotactic research: coarticulation and place assimilation in consonant sequences, both intra- and intersyllabic. Since this issue did not find reflection in the subsequent literature, a brief review may be in order here. A prominent feature of speech is the tendency to coarticulate certain intrasyllabic consonant phoneme sequences (as well as intersyllabic ones, as we will show later). Of interest here is the type referred to as anticipatory coarticulation:

In the ordinary pronunciation of words like "tact" ..., there is only a single silence followed by a single burst, although two stops $/ \mathrm{k} /$ and $/ \mathrm{t} /$ are perceived. The cue for the stop $/ \mathrm{k} /$ must, therefore, be contained in the transitions of the vowel formants preceding the silence. (Halle, Hughes, and Radley, 1957, p. 107)

This phenomenon, which is not language specific, can be explained as follows:

\begin{abstract}
When a stop occurs before another consonant - as in "apt" and "act" - it is unexploded, so that these words are pronounced [æp $t]$ and $\left[æ k^{\circ} t\right]$. This may be regarded as a case of the articulation of the last consonant being anticipated during the closure of the previous consonant. The $[\mathrm{p}]$ in "apt" is unexploded because the closure for the $[\mathrm{t}]$ occurs before the lips come apart. In English an articulator that is not necessarily involved in a given sound will nearly always start moving toward its position in the next sound in which it is the primary articulator. (Ladefoged, 1975, p. 49)
\end{abstract}

Also of interest are intersyllabic consonant sequences, in which stops, or stops and affricates across morpheme boundaries are pronounced in succession. Goldman-Eisler's examples include instances of gemination (identical phonemes): top part, rat tat, and the like. Although phoneme frequency studies show that the voiceless alveolar stop $/ t /$ is the most commonly occurring phoneme in English (Dewey, 1923; Denes, 1963), sequences sharing the same point of articulation are actually infrequent (Denes, 1963, p. 894), whereas multiply different consonant sequences are more common (Lounsbury, 1954 , p. 102). What is important here is that the same coarticulatory principles spelled out for intrasyllabic consonant sequences hold true also for intersyllabic sequences so that in connected speech, the word-final stop remains unreleased (viz. [top ${ }^{\circ}$ part], $\left.\left[r æ t^{\bullet} \mathrm{tæt}\right]\right)$.

A similar phenomenon occurs in cases where the points (rather than the manner) of articulation of adjacent consonants differ, at least in citation form, across morphemes; thus:

It is at word boundaries in connected speech that most cases of phonemic change occur (i.e. change as compared with the phonemic pattern of the isolate word form). Such phonemic variation is found ... particularly, in changes involving modification of the place of articulation, or a combination of voicing and place. (Gimson, 1976, p. 293)

In the type of place assimilation of interest here,

one sound becomes identical with the second. If we utter "horse" and "shoe" individually, we find that "horse" ends in /s/ and "shoe" begins with / $/ \mathbf{s}$. But if we utter them as one word, "horseshoe," the final /s/ of "horse" is assimilated to the initial / $/ \mathbf{s} /$ of "shoe," be- 
coming identical with it in /horšu/. In short, the /s/ disappears. (Stageberg, 1977, p. 32; see also Gimson, 1976, pp. 295-297)

Place assimilation, which, it is to be noted, not only involves continuants such as this shop but stops as well (i.e. that pen, that cup), is then followed by coarticulation, so that the intersyllabic sequences [ðıššp], [ðæppєn], [ðækkıp] (examples adopted from

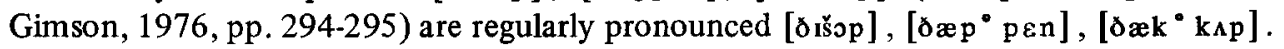

But even in cases where both stops (as in the examples listed) might be released, such as in expressive or emphatic speech, the silent interval is so brief that "in articulating words of the type 'apt,' 'act,' etc., the two compatible closures for the final consonants are only some $20 \mathrm{msec}$ apart" (Kim, 1971, p. 20). The duration of the closure interval of stop consonants in general is of the order of $0.05 \mathrm{sec}$ (see, e.g., Bell-Berti and Harris, 1981; Wieden, 1981) and does not normally exceed $0.10 \mathrm{sec}$ (Halle, Hughes and Radley, 1957; Nooteboom, 1972; Butcher, 1981; Wieden, 1981). Thus neither the silent intervals between stops nor the silent-state portions of stops in the consonant sequences discussed approach magnitudes functional for current pause analysis. Brief pauses can therefore be distinguished from "articulatory" pauses - including even those very brief ones due to post-articulatory repair, e.g., $d$-didn't, th-the (cf. Hieke, 1980) - at a much lower cut-off point than the one suggested by Goldman-Eisler.

In light of the facts that in connected speech a) certain stop consonant sequences of both intra- and intersyllabic types - are coarticulated so that there is only a single release; b) even prolonged articulatory closures do not exceed $0.10 \mathrm{sec}$ and so do not enter magnitudes that could presently be captured through pause analysis (Wieden, 1981 ; cf. also Butcher, 1981, p. 48); and c) certain sibilant sequences as well as certain stop consonant sequences become assimilated and subsequently coarticulated so that there is no phonation gap for the sake of "articulatory shift" (which sound spectrograph analysis of connected speech confirms), the question of a phonation gap as posited by Goldman-Eisler does not arise. With the rationale for the cautious 0.25 sec cut-off point thus brought into question, we must agree with Braehler and Zenz that "the demarcation at $0.25 \mathrm{sec}$ seems to be somewhat arbitrary" $(1975, \mathrm{p} .170)$. It is our position that serious attention to the phonotactic realities of continuous speech may relegate the reservations voiced in regard to articulatory shifts (although they may indeed exist in citation form) to the area of pseudo-phenomena, and that periods of silence below that cut-off point should receive closer attention.

It is our contention that for ranges between 0.13 (a cut-off point below which our analysis does not extend) and $0.25 \mathrm{sec}$, pauses due to articulatory causes are far less frequent than has been assumed up to now. An automatic pause analysis, supplemented by a manual-perceptual one, in the sense of an instance-to-instance auditory check of the machine-registered pauses, can clearly separate psychologically functional pauses from articulatory interruptions in phonation. Such procedures would offer a much more accurate picture of pause profiles in connected discourse and promise some insights as to the extent to which pauses are contextually bound; for, according to current practice, "a simple duration measurement of brief pauses is naive to the extent that it ignores the linguistic context in which the pause occurs" (Rochester, 1975/76, p. 4). Since at least 
in listener detection for short pause durations (under $0.20 \mathrm{sec}$ ) other clues in addition to length are necessary (p. 3), prosodic information should receive more attention. Normal pause expectancy, for instance, can be approached from such a viewpoint, as recent metrical analyses (which posit regular prosodic structures) reveal: "It is BETWEEN intonational phrases (and only between them, we would claim), that one finds potential pauses" (Selkirk, 1980, p. 26). The data analyzed and discussed in the following already give some indication as to what a sensitivity to some of these factors can mean in overall impact on pause research.

\section{EMPIRICAL EVIDENCE FROM CONNECTED DISCOURSE}

A systematic investigation of discourse data in terms of brief pauses only is not available. Some studies have included results on the frequency of pauses $<0.25 \mathrm{sec}$ (cf. Glukhov, 1975; Meinhold, 1967), but their method of pause assessment has been inadequate. Nor has the aspect of pause location been adequately treated, although it is crucial in determining the articulatory or psychological determination of brief pauses.

In order to support our theoretical argumentation, we have analyzed the following sets of data in terms of length, frequency, and location of pauses $0.13-0.25 \mathrm{sec}$ in length:

Poetry readings:

24 native speakers of American English and three native speakers of French reading the French original (63 syllables) and a translation into English (74 syllables) of Paul Verlaine's "Chanson d'automne." The American subjects had either intermediate or advanced knowledge of French.

Political speeches:

Speeches and statements read by the American politicians R. Reagan and J. Carter and by the German politician Helmut Schmidt (total sample size: 8032 syllables).

Both the poetry and political readings have been collected and analyzed in conjunction with other ongoing research projects; but the analyses presented here are not part of those projects.

Tape recordings were made of all speech samples. For each sample a level recording in terms of amplitude of acoustic energy over time was produced: for the poetry by means of a Brïel and Kjaer Audio Frequency Spectrometer (Type 2112) and Level Recorder (Type 2305); for the political speech, partly as for the poetry samples, partly by means of a Fundamental Frequency Meter 650 (F-J Electronics A/S) and Siemens Oscillomink L. In both cases, the measurement criteria for establishing the beginning and end of pauses were determined by a baseline at the ambient and machine noise level of the level recordings. This principle is invoked also by Butcher (1981, p. 62): "In practice it is convenient to adjust the output of the visual record such that the zero line is equivalent 
to the background noise level for each text."

In both cases, longer pauses were determined in keeping with the operational definition given above, and with a cut-off point of $0.27 \mathrm{sec}$ as minimum pause length. Shorter pauses were measured down to a minimum of $0.13 \mathrm{sec}$ and tabulated separately according to length, frequency, and location, although the specifications given above permit shorter measurements. The use of a $0.13 \mathrm{sec}$ cut-off point excludes a great many very short silences from consideration, as Glukhov's (1975) normative data clearly indicate. According to Butcher (1981, p. 48), these short breaks are, however, largely due to "prolonged articulatory closures"; furthermore, they are for the most part imperceptible to listeners (Rochester, 1975/76), and create measurement problems in both manual and automatic methods of analysis (Butcher, 1981, p. 48).

\section{RESULTS}

Response measures for both sets of data, poetry readings and political speeches, have been assembled in Table 1. There are 656 pauses in the corpus of French and English poetry and 803 pauses in the corpus of political speeches; 189 and 67 of these, respectively, are pauses of $0.13-0.25 \mathrm{sec}$ in length.

The first entry of interest for our argument concerning the relevance of pauses shorter than the conventional cut-off point is the percentage of these shorter pauses in the total pauses for each set of data. In the political speeches, the percentage is quite low ( $\leqq$ $10.1 \%$ ) whereas the percentage in the poetry readings is much higher $(\geqq 26.4 \%$ ). There are several plausible reasons for these differences, although their significance is not at issue. The politicians are professional speakers, whereas our poetry readers were ordinary university students; the speeches were given under broadcast conditions, the readings were not; poetic format imposes a specific sequential structure different from the prose of a political text. In any event, the shorter pauses constitute up to almost a third of the pauses in the English version of the poetry readings, and in one reader as many as two thirds of her pauses. The omission of these shorter pauses from temporal analysis of speech must surely be justified with very serious reasons.

A similar argument can be made from a consideration of the percentage of pause time represented by these shorter pauses. These percentages, also shown in Table 1 , are admittedly smaller than those for number of pauses - necessarily so, since they represent the summation of only the shortest pauses in any distribution. In a case such as the one noted above, however, where two thirds of the pauses are these shorter ones, $32.5 \%$ of the reader's pause time was concentrated in these pauses. Again, the omission of such a sizeable portion of the temporal record seriously changes any empirical use thereof.

Nonetheless, the above considerations are only introductory to our primary concern. To recall for the reader, the conventional use of a cut-off point around $0.25 \mathrm{sec}$ has been largely justified on the grounds that the shorter pauses are not psychologically relevant, since they are in large measure of articulatory origin. The two samples of short pauses to be investigated in this regard consisted of 189 from the poetry readings and 67 from the political speeches. It was found that only a small number of these pauses $0.13-$ 


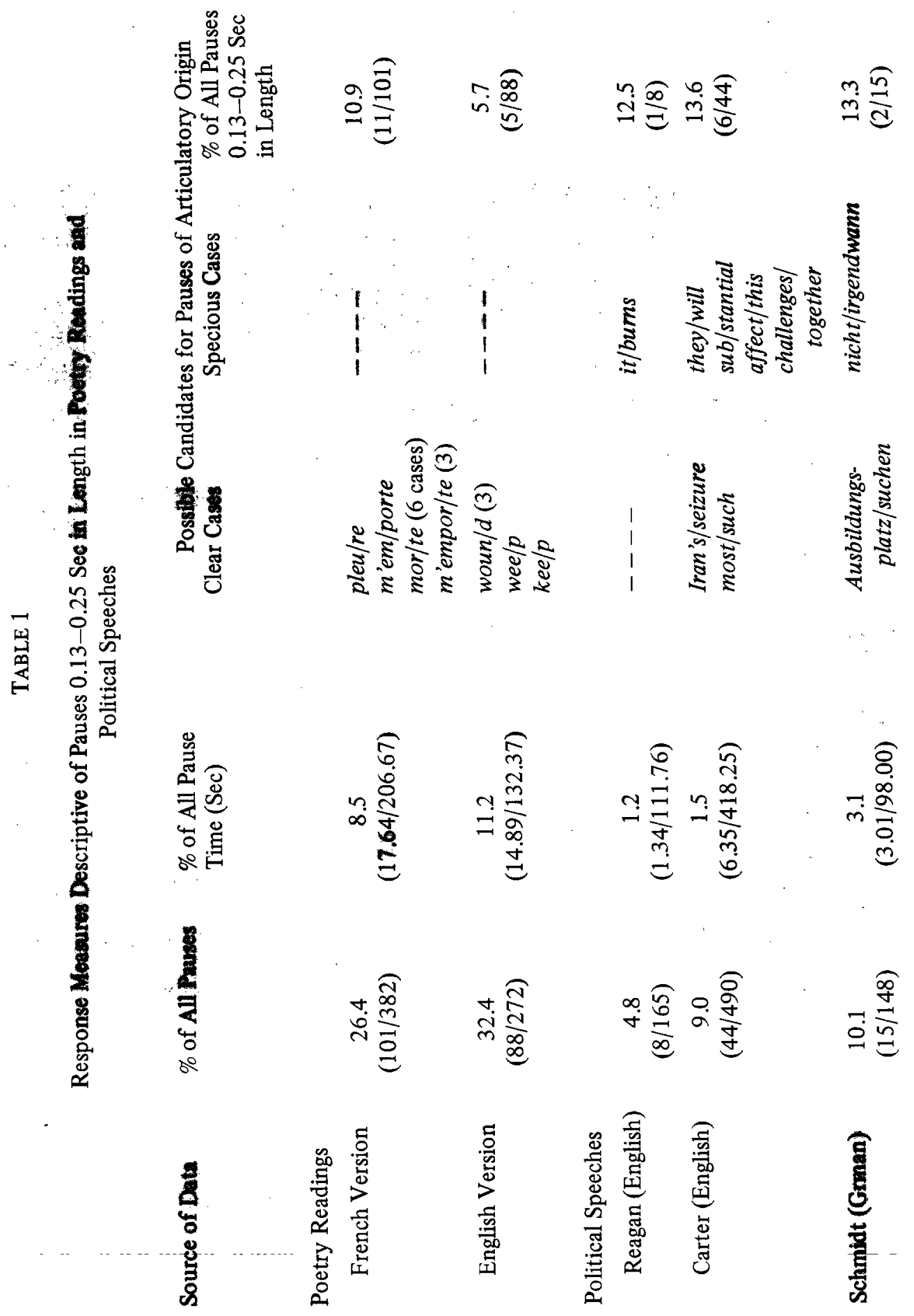


$0.25 \mathrm{sec}$ in length could be plausibly considered in any sense to be of articulatory origin, as Goldman-Eisler contended. Table 1 shows the percentage and actual instances that the authors considered as possible candidates for such a status. In all sub-corpora, these candidates comprise $<15 \%$ of the short pauses (final column of Table 1: \% of All Pauses $0.13-0.25 \mathrm{sec}$ in Length); and of this sub-sample of 25 candidates, six proved to be specious cases. These six, along with the 231 remaining short pauses, all proved to be genuine, clearly perceptible, psychologically tunctional pauses. Hence 237 of the total of 256 short pauses prove not to be of articulatory origin.

More specifically, in the poetry readings, over half the short pauses occurred at the end of poetic lines or at punctuated positions and functionally marked the readings accordingly. Ten more of the shorter pauses occurred between a mistake in reading and its correction. The remaining ones (excluding the 16 clear cases of articulatory origin) were identifiable as rhetorical or expressive pauses used for emphasis, segmentation, or other deliberate effects.

In the political speeches, the majority of the pauses considered as candidates for articulatory origin proved to be specious cases due to very deliberate enunciation. Orators in broadcast settings, speaking persuasively to large crowds, speak emphatically. Butcher has noted "the possibility of the so-called 'emphatic' pause being articulatory in origin" (1981, p. 45). One might also note the possibility of the so-called "articulatory" pause being emphatic in origin.

There are 58 short pauses not of articulatory origin in the political speeches. Of these, 20 are clearly related to constituent boundaries, punctuation, or emphasis. Of the remaining 38, a total of 32 are from Carter's speeches. Stylistically, his public speaking is characterized by a choppy, staccato presentation, to which this prevalence of short pauses contributes.

With regard to the six instances listed in Table 1 as specious cases, we have exercised caution in order to avoid the possibility of prematurely dismissing cases in which articulatory origin of some kind might be operative. The list is, therefore, quite conservative, as examination of the stops (including glottal), alternation of voicing and devoicing, or change in point of articulation shows. Nonetheless, in these instances the specific uses of these transitional processes are not clearly of articulatory origin but appear rather to be psychologically and rhetorically functional.

We come finally to the 19 instances listed in Table 1 as clear cases. It should be noted at once, however, that the processes underlying these articulatory determinations are quite heterogeneous. The only instances clearly of articulatory origin are the adjacent homorganic sibilants (Iran's/seizure and Ausbildungsplatz/suchen). A third case (most/such) involves the alternation of sibilant, stop, and sibilant.

The remaining 16 of these clear cases, as Table 1 again confirms, far from being genuine pauses, reflect the absence of energy display during the silent state portion of ongoing articulation. Hence, this last small sub-set of the clear cases is quite unlike what Goldman-Eisler suggested.

Although Goldman-Eisler concentrated her attention on the articulation of adjacent stops, the two examples given above (Iran's/seizure and Ausbindungsplatz/suchen) manifest a pausal break in the articulation of adjacent continuants. On the other hand, 
the 26 poetry readings in English provide evidence that such is not common in connected discourse. All of the readers of the phrase montonous sound geminated or "linked" the adjacent sibilants without availing themselves of the alternative option of a pausal break. This finding is in accordance with our expectations in view of the phonotactic realities reviewed earlier in this paper.

\section{CONCLUSION}

The concept of articulatory pause historically traceable to Goldman-Eisler most certainly needs to be further reviewed and questioned. We have found that short pauses $(0.13-0.25 \mathrm{sec})$ are indeed psychologically functional. Analyses of spontaneous speech genres will be needed in order to throw further light on the specific function of such pauses, since the empirical data presented here are limited to reading only.

We would hope our evidence is cogent for the reader: Exclusion of short pauses $(0.13-0.25 \mathrm{sec})$ from analysis on articulatory grounds is completely unjustified. However, comparability with extant research data currently demands consideration for traditional higher cut-off points. New projects in this area of research cannot ignore the psychological function of shorter pauses. Our analyses clearly indicate that a minimum pause duration of somewhat over $0.10 \mathrm{sec}$ is to be recommended.

\section{REFERENCES}

BELL-BER TI, F. and HARRIS, K.S. (1981). A temporal model of speech production. Phonetica, 38, 9-20.

Boomer, D.S. and DitTmanN, A.T. (1962). Hesitation pauses and juncture pauses in speech. Language and Speech, 5, 215-220.

BRAEHLER, E. and ZENZ, H. (1975). Artifacts in the registration and interpretation of speechprocess variables. Language and Speech, 18, 166-179.

Butcher, A. (1981). Aspects of the Speech Pause: Phonetic Correlates and Communicative Functions. Institut für Phonetik, Universität Kiel, Arbeitsberichte Nr. 15.

BUtTerworth, B. (ed.). (1980). Language Production, vol. 1, Speech and Talk (London), pp. 155-176.

COWAN, J.M. and BLOCH, B. (1948). An experimental study of pause in English grammar. American Speech, 23, 89-99.

Dalton, P. and HARDCASTLE, W.J. (1977). Disorders of Fluency and Their Effects on Communication (London).

DECher T, H.W. and RAUPACH, M. (eds.). (1980a). Temporal Variables in Speech: Studies in Honour of Frieda Goldman-Eisler (The Hague).

DECheR T, H.W. and RAUPACH, M. (eds.). (1980b). Toward a Cross-Linguistic Assessment of Speech Production (Frankfurt).

DENES, P.B. (1963). On the statistics of spoken English. Journal of the Acoustical Society of America, 35, 892-904.

DEWEY, G. (1923). Relative Frequency of English Speech Sounds (Cambridge).

ESSER, U. (1977). Untersuchungen zum Pausenverhalten in der spontanen und experimentell-provozierten Sprachproduktion. Dissertation, University of Leipzig. 
Gimson, A.-C. (1976). An Introduction to the Pronunciation of English, 2nd ed. (London).

GLUKHOV, A.A. (1975). Statistical analysis of speech pauses for Romance and Germanic languages. Soviet Physics: Acoustics, 21, 71-72.

GoldmaN-EISLER, F. (1958). Speech production and the predictability of words in context. Quarterly Journal of Experimental Psychology, 10, 96-102.

Goldma N-EISLER, F. (1968). Psycholinguistics: Experiments in Spontaneous Speech (New York).

GrosjeAN, F. and Deschamps, A. (1975). Analyse contrastive des variables temporelles de l'anglais et du français: Vitesse de parole et variables composantes, phénomènes d'hesitation. Phonetica, 31, 144-184.

HALle, M., HUGHES, G.W. and RADLEY, J.P.A. (1957). Acoustic properties of stop consonants. Journal of the Acoustical Society of America, 29, 107-116.

HENZE, R. (1953). Experimentelle Untersuchungen zur Phänomenologie der Sprachgeschwindigkeit. Zeitschrift für experimentelle und angewandte Psychologie, 1, 214-243.

HIEKE, A.E. (1980). Aspects of native and non-native fluency skills. Dissertation, University of Kansas.

KIM, C. (1971). Experimental phonetics. In. W.O. Dingwall (ed.), A Survey of Linguistic Science (College Park, MD), pp. 16-128.

LADEFOGED, P. (1975). A Course in Phonetics (New York).

LAY, C.H. and PAIVIO, A. (1969). The effects of task difficulty and anxiety on hesitations in speech. Canadian Journal of Behavioural Science, 1, 25-37.

LeviN, H. and Silverman, I. (1965). Hesitation phenomena in children's speech. Language and Speech, 8, 67-85.

LEVIN, H., SILVERMAN, I. and FORD, B. (1967). Hesitations in children's speech during explanation and description. Journal of Verbal Learning and Verbal Behavior, 6, 560-564.

LOUNSBURY, F.G. (1954). Transitional probability, linguistic structure, and systems of habitfamily hierarchies. In C.E. Osgood and T.A. Sebeok (eds.), Psycholinguistics: A Survey of Theory and Research Problems (Baltimore), pp. 93-101.

MACLAY, H. and OSGOOD, C. (1959). Hesitation phenomena in spontaneous English speech. Word, $15,19-44$.

MARTIN, J.G. (1970). On judging pauses in spontaneous speech. Journal of Verbal Learning and Verbal Behavior, 9, 75-78.

MEINHOLD, G. (1967). Quantität und Häufigkeit von Pausen in gelesenen deutschen Texten in Zusammenhang mit dem Sprechtempo. Wissenschaftliche Zeitschrift der Friedrich-SchillerUniversität Jena, 1, 107-111.

NOотевоOM, S.G. (1972). A survey of some investigations into the temporal organization of speech. IPO Annual Progress Report, 7, 17-29 (Institute of Perception Research, Eindhoven).

O'CONNELL, D.C. and KowAL, S. (1983). Pausology. In W.A. Sedelow and S.Y. Sedelow (eds), Computers in Language Research, 2 (Berlin).

O'ConNell, D.C., Kowal, S. and HörmanN, H. (1969). Semantic determinants of pauses. Psychologische Forschung, 33, 50-67.

ROCHESTER, S.R. (1975/76). Defining the silent pause in speech. Journal of the Ontario Speech and Hearing Association, 8, 14 .

SELKIRK, E.O. (1980). On prosodic structure and its relation to syntactic structure. Indiana University Linguistics Club.

SiEgmaN, A.W. (1979). Cognition and hesitation in speech. In Siegman and Feldstein (1979), pp. $151-178$.

Siegman, A.W. and FeldSTEIN, S. (eds.). (1979). Of Speech and Time: Temporal Speech Patterns in Interpersonal Contexts (Hillsdale, N.J.).

SIEgMAN, A.W. and POPE, B. (1966). Ambiguity and verbal fluency in the TAT. Journal of Consulting Psychology, 30, 239-245.

STA GE BERG, N.C. (1977). An Introductory English Grammar, 3rd ed. (New York).

WIEDEN, W. (1981). Elemente der temporalen Organisation von Englischer Connected Speech: Eine 
experimental-linguistische Studie. Salzburger Studium zur Anglistik und Amerikanistik. Institut für Anglistik und Amerikanistik Universität Salzburg.

WILKES, A.L. and KENNEDY, R.A. (1969). Relationship between pausing and retrieval latency in sentences of varying grammatical form. Journal of Experimental Psychology, 79, 241-245. 